\title{
$\mathrm{Pt} / \mathrm{Co} / \mathrm{Ba} / \mathrm{Al}_{2} \mathrm{O}_{3}$ 에 $\mathrm{Fe}$ 첨가가 수소 풍부 $\mathrm{NSR}$ 반응성에 미치는 영향 \\ 김진걸 $\cdot$ 전지용 ${ }^{2} \cdot$ 김성수 $^{\dagger \dagger}$ \\ ${ }^{1}$ 순천향대학교 나노화공과, ${ }^{2}$ (주)이엔드디 기술연구소, \\ ${ }^{3}$ 한국에너지기술연구원 폐기물 에너지 연구센터
}

\section{Effect of Fe Addition on Hydrogen Rich NSR Kinetics over $\mathrm{Pt} / \mathrm{Co} / \mathrm{Ba} / \mathrm{Al}_{2} \mathrm{O}_{3}$ Catalyst}

\author{
JINGUL KIM ${ }^{1}$, JIYONG JEON ${ }^{2}$, SEONGSOO KIM ${ }^{3 \dagger}$ \\ ${ }^{1}$ Dept. of Chemical Eng., Soonchunhyang University \\ ${ }^{2}$ E\&D Corporation Ltd., Seoul \\ ${ }^{3}$ Waste Energy Research Center, Korea Institute of Energy Research
}

\begin{abstract}
Thermal aging effect on NSR kinetics was studied over $\mathrm{Pt} / \mathrm{Co} / \mathrm{Fe} / \mathrm{Ba} / \mathrm{Al}_{2} \mathrm{O}_{3}$ catalyst. The amount of $\mathrm{NO}_{\mathrm{x}}$ uptake over $\mathrm{Pt} / \mathrm{Co} / \mathrm{Ba} / \mathrm{Al}_{2} \mathrm{O}_{3}$ calcined at $400^{\circ} \mathrm{C}$ increased with increasing NSR temperature from $200^{\circ} \mathrm{C}$ to $400^{\circ} \mathrm{C}$, where amount of $\mathrm{NO}_{\mathrm{x}}$ uptake is the highest at $400^{\circ} \mathrm{C}$ with mol ratio of $\mathrm{NO}_{\mathrm{x}} / \mathrm{Ba}=0.5$. Thereafter, the amount of $\mathrm{NO}_{\mathrm{x}}$ uptake at $400{ }^{\circ} \mathrm{C}$ decreased with the higher calcination temperature, where $\mathrm{Pt} / \mathrm{Co} / \mathrm{Ba} / \mathrm{Al}_{2} \mathrm{O}_{3}$ catalyst calcined at $700^{\circ} \mathrm{C}$ showed an amount of $\mathrm{NO}_{\mathrm{x}}$ uptake with the mol ratio of $\mathrm{NO}_{\mathrm{x}} / \mathrm{Ba}=0.062$.

Result of XRD and NSR showed that $\mathrm{Fe}$ addition into $\mathrm{Pt} / \mathrm{Co} / \mathrm{Ba} / \mathrm{Al}_{2} \mathrm{O}_{3}$ suppressed sintering of $\mathrm{Pt}$ crystallites and make $\mathrm{NO}_{\mathrm{x}}$ uptake larger, compared to no addition of $\mathrm{Fe}$ into $\mathrm{Pt} / \mathrm{Co} / \mathrm{Ba} / \mathrm{Al}_{2} \mathrm{O}_{3}$ catalyst. From $\mathrm{BET}$ result, it was found that the change of specific surface area was relatively small by the thermal aging process. Therefore, it was found that the sintering of Pt crystallites caused the decrease of $\mathrm{NO}_{\mathrm{x}}$ uptake during NSR reaction and Fe played a role to suppress the sintering process of Pt crystallites caused by thermal aging.
\end{abstract}

Key words : $\mathrm{Fe}\left(\right.$ 철), $\mathrm{NO}_{\mathrm{x}}$ (질소산화물), Sintering(소결), Thermal aging(열화) $\mathrm{NSR}\left(\mathrm{NO}_{\mathrm{x}}\right.$ 흡장 탈착)

\section{1. 서 론}

질소산화물은 대기 중 오존의 발생원으로서 광화 학적 작용을 일으켜 스모그를 발생시키며 인체건강 에 매우 큰 영향을 미치는 것으로 알려져 있다. 대형 디젤 연소 엔진에서 사용하는 희박연소기술은 높은 공기/연료비에서 연소가 진행되기 때문에 연소효율 이 우수하지만, 배출가스에 산소가 다량 함유되어 있

\footnotetext{
${ }^{\dagger}$ Corresponding author : sskim@kier.re.kr [ 접수일 : 2012.10.22 수정일 : 2012.12.24 게재확정일 : 2012.12.31 ] Copyright (c) 2012 KHNES
}

으므로 기존의 삼원 촉매 기술로는 포함된 $\mathrm{NO}_{\mathrm{x}}$ 를 제 거하기가 어려운 것으로 알려져 있다.

이에 따라, 보다 효과적이며 진보된 기술이 요구 되며, 질소산화물 저감을 위해 요소(Urea) SCR (선 택적 촉매 환원법), $\mathrm{HC}$ (탄화수소)-SCR 및 $\mathrm{NO}_{\mathrm{x}}$ 흡장환원법 $\left(\mathrm{NO}_{\mathrm{x}}\right.$ storage reduction : $\left.\mathrm{NSR}\right)$ 이 연소 엔진에 서 발생하는 $\mathrm{NO}_{\mathrm{x}}$ 를 정화하는 신기술인 것으로 알려 져 있다 ${ }^{1-10)}$.

요소(Urea) $\mathrm{SCR}$ 은 $\mathrm{NO}_{\mathrm{x}}$ 정화특성은 우수하나 후처 리 장치의 볼륨이 크고 별도의 요소 저장조가 필요하 며 요소의 보충 및 요소 동결 등의 해결 과제가 있다. 
흡장-환원 촉매 $\left(\mathrm{NO}_{\mathrm{x}}\right.$ storage reduction : $\left.\mathrm{NSR}\right)$ 기술 은 희박조건인 산화 분위기에서는 $\mathrm{BaO}$ 에 $\mathrm{NO}_{\mathrm{x}}$ 을 흡 장시켜 제거하고, 연속하여 연료를 분사하여 완성되 는 수소 농후조건인 환원 분위기에서 흡장된 질소 산 화물을 환원시켜 제거하는 기술이다 ${ }^{5)}$ NSR 기술은 희박 연소 조건의 엔진에서 배출되는 $\mathrm{NO}_{\mathrm{x}}$ 를 제거하 기 위하여, 후처리장치에서 주기적으로 연료 희박/수 소 농후 조건을 반복하는 구성으로 이루어져 있다 ${ }^{3-7)}$.

기존 Toyota에 의하여 개발된 NSR 촉매인 $\mathrm{Pt} /$ $\mathrm{Ba} / \mathrm{Al}_{2} \mathrm{O}_{3}$ 촉매의 성능은 비활성화에 의하여 감소하 며, 배기가스에 포함된 $\mathrm{SO}_{x}$ 와 촉매 온도가 상승하여 발생되는 열화에 의한 피독 현상이 비활성화의 주요 원인인 것으로 알려져 있다. 그중 $\mathrm{SO}_{\mathrm{x}}$ 는 촉매성분에 황화물를 형성하여 촉매 활성분을 감소시키고, 열화 는 금속의 결정 성장을 진행시키는 것으로 알려져 있다 ${ }^{3-6)}$. 따라서, 보다 우수한 촉매를 위하여 이러한 비활성화에 의한 촉매 성능 감소를 개선하기 위한 연구가 필요한 실정이다.

$\mathrm{Fe}$ 성분 첨가는 삼원촉매의 열화 내구성을 향상시 키는 것으로 보고되며, $\mathrm{Pt} / \mathrm{Ba} / \mathrm{Al}_{2} \mathrm{O}_{3}$ 촉매에 $\mathrm{Fe}$ 첨가 시에는 촉매에 흡착된 sulfur를 제거하는 재생온도가 감소하므로, 황(sulfur) 피독을 감소, 방지 하는 효과 가 있는 것으로 보고되었으며, FTIR 연구에서 $\mathrm{Fe}$ 첨 가가 NSR 촉매의 내구성을 증가하는 것으로 보고되 었다,5). 그러나 이미 발표된 이러한 결과들은 $\mathrm{SO}_{\mathrm{x}}$ 및 열화에 따른 NSR 반응 속도 변화와, 이에 따른 촉매 특성의 변화를 구체적으로 보고하고 있지 않다. 이에 따라, 흡장성능이 기존의 $\mathrm{Pt} / \mathrm{Ba} / \mathrm{Al}_{2} \mathrm{O}_{3}$ 촉매보다 우수한 것으로 발표된 $\mathrm{Pt} / \mathrm{Co} / \mathrm{BaO} / \mathrm{Al}_{2} \mathrm{O}_{3}$ 촉매에 $\mathrm{Fe}$ 를 첨가하여 제조된 $\mathrm{Pt} / \mathrm{Co} / \mathrm{Fe} / \mathrm{Ba} / \mathrm{Al}_{2} \mathrm{O}_{3}$ 촉매가 $\mathrm{SO}_{\mathrm{x}}$ 존재 및 열화 조건에서 $\mathrm{NO}_{\mathrm{x}}$ 흡장-환원 반응 특성에 미치 는 영향을 연구하였다.

\section{2. 실 험}

\section{1 촉매 제조}

담체는 Axens사의 $\gamma$-Alumina(SPH557, $303 \mathrm{~m}^{2} / \mathrm{g}$ )
Table 1 Reaction Condition of NSR Experiment

\begin{tabular}{l|c|c}
\hline \hline & Lean Condition & Rich Condition \\
\hline Temperature $\left({ }^{\circ} \mathrm{C}\right)$ & 250,400 & 250,400 \\
\hline Flow rate $(\mathrm{ml} / \mathrm{min})$ & 250 & 30 \\
\hline Space Velocity $\left(\mathrm{Hr}^{-1}\right)$ & 225,000 & 26,500 \\
\hline $\mathrm{NO}(\mathrm{ppm})$ & 1,200 & \\
\hline $\mathrm{SO}_{\mathrm{x}}(\mathrm{ppm})$ & 60 & \\
\hline $\mathrm{O}_{2}(\%)$ & 8 & \\
\hline $\mathrm{CO}(\%)$ & & 11.97 \\
\hline $\mathrm{H}_{2}(\%)$ & & 7376 \\
\hline $\mathrm{CO}_{2}(\%)$ & & 8.23 \\
\hline $\mathrm{CH}_{4}(\%)$ & & 3.46 \\
\hline $\mathrm{C}_{2} \mathrm{H}_{4}(\%)$ & & 1.79 \\
\hline \multicolumn{2}{|l}{}
\end{tabular}

을 사용하였고, 전구체는 Aldrich사의 $\mathrm{Ba}\left(\mathrm{NO}_{3}\right)_{2} \cdot \mathrm{xH}_{2} \mathrm{O}$, $\mathrm{Co}\left(\mathrm{NO}_{3}\right) \cdot 6 \mathrm{H}_{2} \mathrm{O}, \mathrm{Fe}\left(\mathrm{NO}_{3}\right)_{3} \cdot 9 \mathrm{H}_{2} \mathrm{O}, \mathrm{PM}$ research 사의 $\mathrm{Pt}\left(\mathrm{NH}_{3}\right)_{3}\left(\mathrm{NO}_{3}\right)_{3}$ 를 사용하였다, $\gamma$-Alumina에 $\mathrm{BaO}$ 가 $30 \%$ 의 질량비로 생성되도록 $\mathrm{Ba}$ 전구체를 함침시키 고 $400^{\circ} \mathrm{C}$ 상태로 3 시간 소성하여 $30 \% \mathrm{BaO} / \mathrm{Al}_{2} \mathrm{O}_{3}$ 를 제조한다. $\mathrm{Pt}\left(\mathrm{NH}_{3}\right)_{3}\left(\mathrm{NO}_{3}\right)_{3}$ 를 사용하여 $3 \%$ 의 $\mathrm{Pt}$ 를 함 침하여 $400^{\circ} \mathrm{C}$ 로 1 시간 소성하고 Cobalt 전구체를 사 용하여 $2 \% \mathrm{Co}$ 를 함침한 후 $5500^{\circ} \mathrm{C}$ 에서 1 시간 소성한 다. 연속하여 $\mathrm{Fe}$ 전구체를 사용하여 $10 \% \mathrm{Fe}$ 를 함침 한 후, $400^{\circ} \mathrm{C}$ 에서 1 시간동안 소성하여 $3 \% \mathrm{Pt} / 2 \% \mathrm{Co} /$ $10 \% \mathrm{Fe} / \mathrm{Ba} / \mathrm{Al}_{2} \mathrm{O}_{3}$ 촉매를 제조하였으며, 제조된 촉매 의 비중은 $0.625 \mathrm{~cm}^{3} / \mathrm{g}$ 로 나타난다.

\subsection{NSR 실험 방법}

Table 1에 나타난 실험 조건은 디젤자동차 엔진에

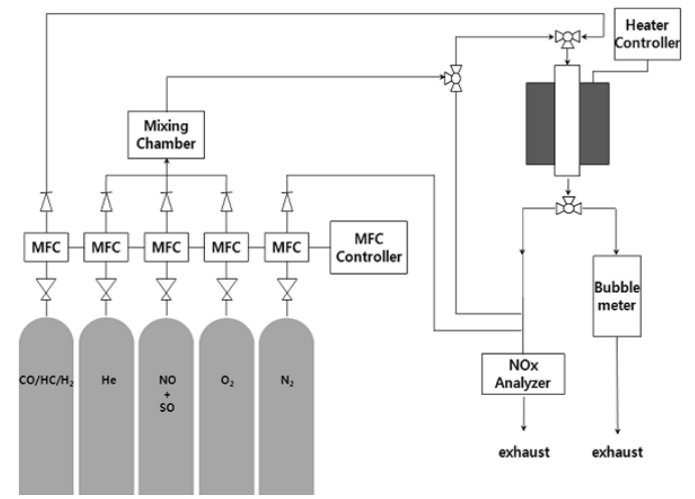

Fig. 1 Schematic experimental apparatus 
서 배출되는 배기가스 조건과 유사한 반응기 조건으 로 설정되었다. MFC 장치(Brooks 5850)를 사용하여 공급 유량을 조절하였으며, 실험에 사용된 NSR 반응 장치의 구성을 Fig. 1에 제시하였다.

실험은 희박조건과 농후 조건을 반복하여 실험하 였으며, NSR 반응 진행에 따른 $\mathrm{NO}_{\mathrm{x}}$ 농도 변화를 분 석하기 위하여 Siemens사의 $\mathrm{NO}_{\mathrm{x}}$ 분석기(Ultramat 23)를 사용하였다.

\section{3 촉매 특성 분석}

촉매 열화 진행도 분석을 위하여 $3 \% \mathrm{Pt} / 2 \% \mathrm{Co} / 10 \% \mathrm{Fe} /$ $\mathrm{BaO} / \mathrm{Al}_{2} \mathrm{O}_{3}$ 촉매를 $400^{\circ} \mathrm{C}, 500^{\circ} \mathrm{C}, 600^{\circ} \mathrm{C}, 700^{\circ} \mathrm{C}, 850^{\circ} \mathrm{C}$ 로 소성한 뒤, 시료의 열화 진행에 따른 결정 성장 변 화를 관찰하기 위하여 $\mathrm{XRD}$ 분석을 하였다. 상기 열 화 촉매를 Flowprep 060 장비(Micromeritics)로 $\mathrm{N}_{2}$ 하에 $400^{\circ} \mathrm{C}$ 에서 2 시간 전처리를 한 후 Gemini 2375 (Micromeritics)를 사용하여 시료의 비표면적 변화를 측정하였다.

\section{3. 결과 및 고찰}

\section{1 저온 $\left(200^{\circ} \mathrm{C} \sim 400^{\circ} \mathrm{C}\right) \mathrm{NSR}$}

디젤엔진의 특성상 초기 가동시 배기가스온도가 낮으므로 저온에서의 흡장성능 평가가 요구된다.

$400^{\circ} \mathrm{C}$ 에서 소성한 $3 \% \mathrm{Pt} / 2 \% \mathrm{Co} / \mathrm{BaO} / \mathrm{Al}_{2} \mathrm{O}_{3}$ 촉매를 사용하여 저온 배기 가스 조건인 $200^{\circ} \mathrm{C}-400^{\circ} \mathrm{C}$ 에서 측정한 NSR 결과가 Fig. 2 에 나타난다. 저온 $\left(200^{\circ} \mathrm{C}\right)$ 희박조건에서 촉매의 흡장량이 가장 작으며 NSR 반 응온도에 비례하여 흡장 성능이 증가하여 $400^{\circ} \mathrm{C}$ 에서 촉매의 $\mathrm{NO}_{\mathrm{x}}$ 흡장량이 가장 큰 것으로 나타난다.

$3 \% \mathrm{Pt} / 2 \% \mathrm{Co} / 10 \% \mathrm{Fe} / \mathrm{BaO} / \mathrm{Al}_{2} \mathrm{O}_{3}$ 촉매를 사용한 NSR 반응 온도 변화에 따른 결과가 Fig. 3에 나타난다. Fig. 2에서와 같이, 저온 $\left(200^{\circ} \mathrm{C}\right)$ 희박조건에서 촉매 의 흡장량이 가장 작으며 반응온도에 비례하여 흡장 성능이 증가하여 $400^{\circ} \mathrm{C}$ 에서 촉매의 흡장량이 가장 큰 것을 관찰할 수 있다.

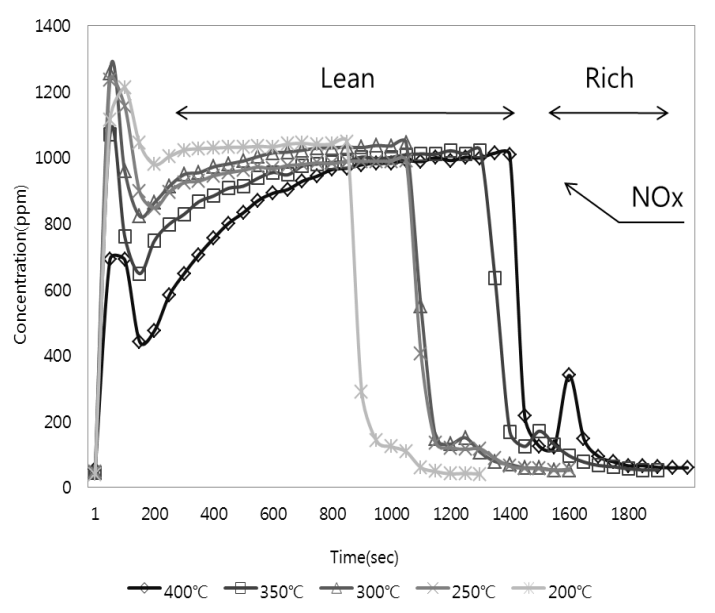

Fig. 2 Effect of NSR reaction temperature over $3 \% \mathrm{Pt} / 2 \% \mathrm{Co} / \mathrm{BaO} / \mathrm{A}_{2} \mathrm{O}_{3}$ calcined at $400^{\circ} \mathrm{C}$

Fig. 3 결과를 Fig. 2 결과와 비교할시, $\mathrm{Fe}$ 첨가된 시료의 NSR 농후조건 실험에서 $\mathrm{NO}_{\mathrm{x}}$ 검출선 크기가 상대적으로 작으므로, 흡장된 $\mathrm{NO}_{\mathrm{x}}$ 가 농후 조건에서 더 많이 질소로 환원되어 배출된 것으로 판단되고, 비환원되고 배출되는 $\mathrm{NO}_{\mathrm{x}}$ 의 양이 상대적으로 감소 하는 것으로 나타난다. 따라서, $\mathrm{Fe}$ 의 첨가는 희박조 건에서 저장된 $\mathrm{NO}_{\mathrm{x}}$ 가 농후조건에서 환원되는 반응 성을 증가시키는 것으로 관측된다.

Fig. 2, Fig. 3 에 제시된 저온 $\left(200^{\circ} \mathrm{C}-400^{\circ} \mathrm{C}\right)$ 에서 $\mathrm{Fe}$

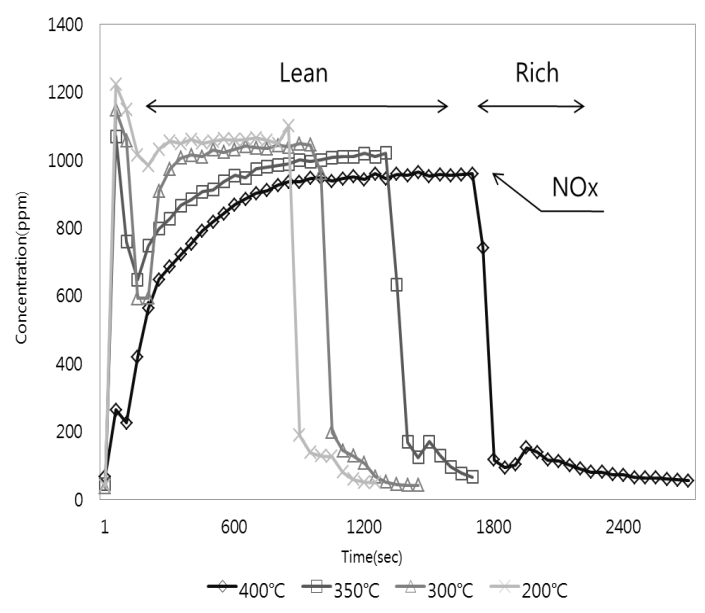

Fig. 3 Effect of NSR reaction temperature over $3 \% \mathrm{Pt} / 2 \% \mathrm{Co} /$ $10 \% \mathrm{Fe} / \mathrm{BaO} / \mathrm{Al}_{2} \mathrm{O}_{3}$ calcined at $400^{\circ} \mathrm{C}$ 
Table 2 Effect of Promoter on NSR Kinetics over BaO/ $\mathrm{Al}_{2} \mathrm{O}_{3}$

\begin{tabular}{c|c|c|c|c|c}
\hline \hline \multirow{7}{*}{} & $\begin{array}{c}\mathrm{Pt} \\
(\%)\end{array}$ & $\begin{array}{c}\mathrm{Co} \\
(\%)\end{array}$ & $\begin{array}{c}\mathrm{Fe} \\
(\%)\end{array}$ & $\begin{array}{c}\mathrm{NSR} \text { Temp. } \\
\left({ }^{\circ} \mathrm{C}\right)\end{array}$ & $\begin{array}{c}\mathrm{NO}_{\mathrm{x}} \text { uptake } \\
\left(\mathrm{NO}_{\mathrm{x}} \text { mole/ }\right. \\
\mathrm{Ba} \text { mole })\end{array}$ \\
\hline \multirow{5}{*}{$30 \% \mathrm{BaO} /$} & 3 & 2 & - & 200 & - \\
\cline { 2 - 7 } $\mathrm{Al}_{2} \mathrm{O}_{3}$ & 3 & 2 & - & 250 & 0.046 \\
\cline { 2 - 6 } & 3 & 2 & - & 300 & 0.08 \\
\cline { 2 - 6 } & 3 & 2 & - & 350 & 0.19 \\
\cline { 2 - 6 } & 3 & 2 & - & 400 & 0.41 \\
\cline { 2 - 6 } & 3 & 2 & 10 & 250 & - \\
\cline { 2 - 6 } & 3 & 2 & 10 & 300 & 0.07 \\
\cline { 2 - 6 } & 3 & 2 & 10 & 350 & 0.14 \\
\cline { 2 - 6 } & 3 & 2 & 10 & 400 & 0.50 \\
\hline
\end{tabular}

첨가에 따른 흡장성능을 Table 2에 나타내었다. 저온 $\left(250^{\circ} \mathrm{C}-350^{\circ} \mathrm{C}\right)$ 에서는 $\mathrm{Fe}$ 첨가가 $\mathrm{NO}_{\mathrm{x}}$ 흡장에 미치는 영향이 작지만, $400^{\circ} \mathrm{C}$ 에서는 $\mathrm{Fe}$ 첨가에 따라 흡장량 이 상대적으로 증가하는 것을 알 수 있다.

\section{2 열화 촉매 NSR}

자동차 엔진의 온도는 디젤의 경우, $500 \sim 700^{\circ} \mathrm{C}$ 정 도에서 압축된 연료가 폭발하고 엔진 내부의 온도는 최대 $2800^{\circ} \mathrm{C}$ 까지도 상승하므로 배기가스의 온도 또 한 상승한다. 따라서, 배기가스 정화용 촉매가 고온 열화 조건에서 활성을 유지하는 것이 요구되며, 열화 에 따른 촉매성능의 변화와 열화를 억제하는 첨가물 의 개발이 요구된다.

열화에 따른 촉매 성능을 관찰하기 위하여, $3 \% \mathrm{Pt} /$ $2 \% \mathrm{Co} / \mathrm{BaO} / \mathrm{Al}_{2} \mathrm{O}_{3}$ 의 촉매를 $400^{\circ} \mathrm{C}, 500^{\circ} \mathrm{C}, 600^{\circ} \mathrm{C}, 700^{\circ} \mathrm{C}$ 로 소성(Calcination)한 후 $400^{\circ} \mathrm{C}$ 에서 흡장 성능을 측 정하였다. Fig. 4에 나타난 바와 같이 고온에서 소성 과정을 통하여 열화된 촉매일수록 $\mathrm{NO}_{\mathrm{x}}$ 흡장성능이 감소함을 알 수 있다.

Fig. 4에서 사용한 촉매에 $10 \% \mathrm{Fe}$ 를 첨가한 $3 \% \mathrm{Pt} / 2 \% \mathrm{Co} / \mathrm{BaO} / \mathrm{Al}_{2} \mathrm{O}_{3}$ 를 $400,500,600,700,850^{\circ} \mathrm{C}$ 에서 소성하여 열화 처리한 촉매의 $\mathrm{NO}_{\mathrm{x}}$ 흡장 결과를 Fig. 5에 도시하였다.

내열성을 개선시킬 목적으로 첨가된 $\mathrm{Fe}$ 는 $\mathrm{NO}_{\mathrm{x}}$ 를

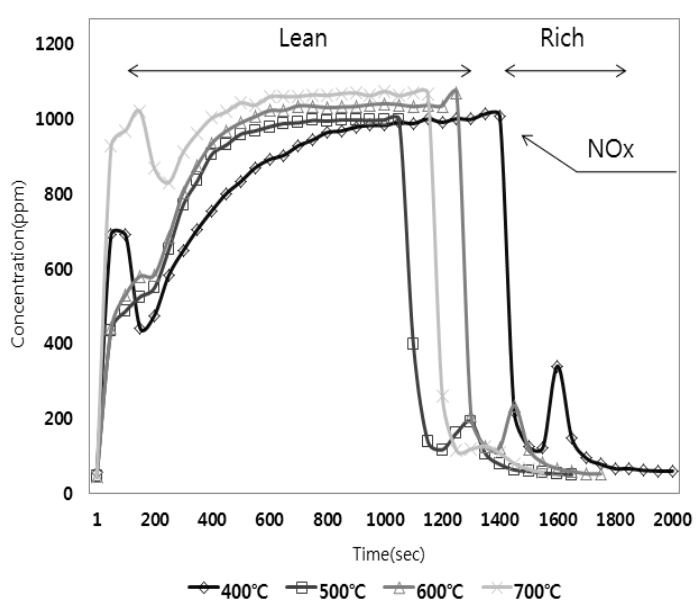

Fig. $4 \mathrm{NSR}$ at $400^{\circ} \mathrm{C}$ of $3 \% \mathrm{Pt} / 2 \% \mathrm{Co} / \mathrm{BaO} / \mathrm{Al}_{2} \mathrm{O}_{3}$ calcined over $400^{\circ} \mathrm{C}$

흡장하지 않지만, $\mathrm{NO}_{\mathrm{x}}$ 로의 환원제 확산을 증가시키 는 역할을 하여 표층 $\mathrm{Ba}$ 에서 심층 $\mathrm{Ba}$ 로 $\mathrm{NO}_{\mathrm{x}}$ 흡장성 을 증가시키는 것으로 알려져 있다 ${ }^{8)}$. Fig. 4에 제시 된 흡장 결과와 비교하여, 소성 열화온도가 높은 촉 매일수록 흡장성능이 증가하는 것을 관찰할 수 있으 며, 연속되는 연료 농후조건에서는 열화에 따른 $\mathrm{NO}_{\mathrm{x}}$ 환원성도 증가하는 것을 관찰할 수 있다. 따라서, Fig. 4와 Fig. 5에 제시된 결과를 비교해 본 결과, Fe가 함침 된 촉매가 $\mathrm{Fe}$ 가 함침되지 않은 촉매보다 열화 조 건에서 더욱 우수한 $\mathrm{NO}_{\mathrm{x}}$ 흡장 특성을 나타내었다.

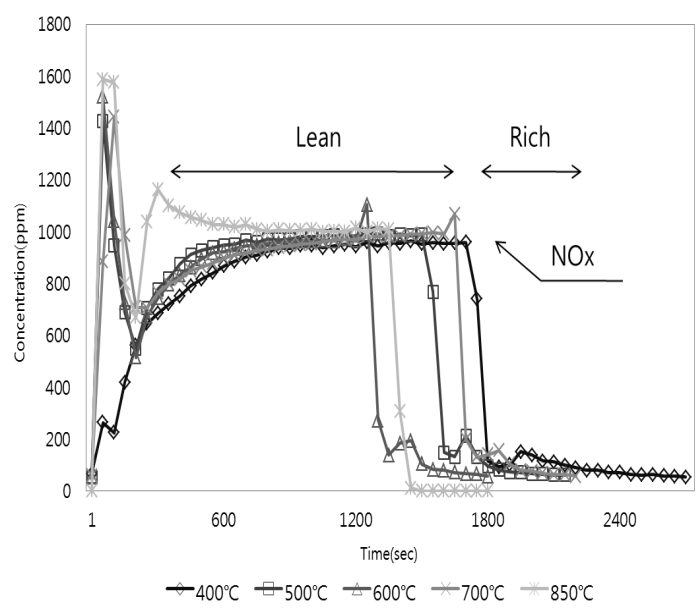

Fig. $5 \mathrm{NSR}$ at $400^{\circ} \mathrm{C}$ of $3 \% \mathrm{Pt} / 2 \% \mathrm{Co} / 10 \% \mathrm{Fe} / \mathrm{BaO} / \mathrm{Al}_{2} \mathrm{O}_{3}$ calcined over $400^{\circ} \mathrm{C}$. 


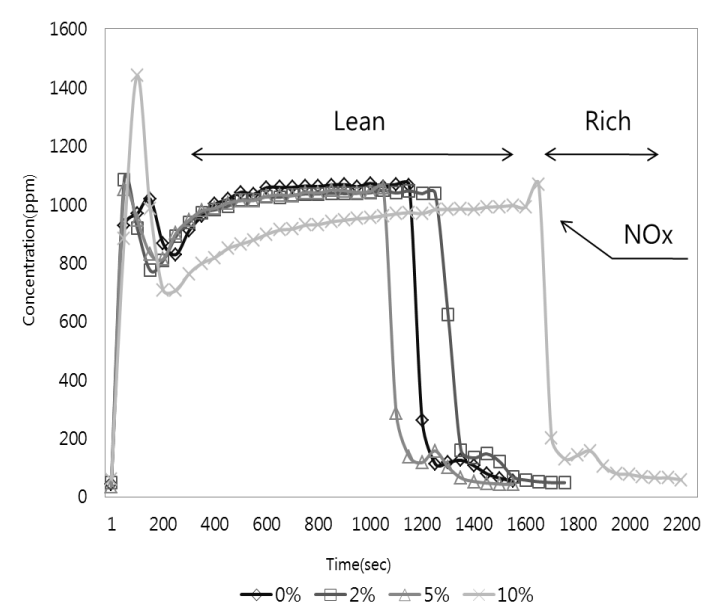

Fig. 6 Effect of iron amount on NSR at $400^{\circ} \mathrm{C}$ over $3 \% \mathrm{Pt} /$ $2 \% \mathrm{Co} / 10 \% \mathrm{Fe} / \mathrm{BaO} / \mathrm{Al}_{2} \mathrm{O}_{3}$ calcined at $700^{\circ} \mathrm{C}$

$\mathrm{Pt} / \mathrm{Co} / \mathrm{Fe} / \mathrm{Ba} / \mathrm{Al}_{2} \mathrm{O}_{3}$ 촉매는 $400^{\circ} \mathrm{C}$ 소성된 촉매와 비교하여 $700^{\circ} \mathrm{C}$ 에서 열화한 촉매의 $\mathrm{NO}_{\mathrm{x}}$ 흡장면적이 $50 \%$ 정도 감소하는 것으로 나타난다. 따라서, $700^{\circ} \mathrm{C}$ 에서 $\mathrm{Fe}$ 량에 따른 $\mathrm{NSR}$ 성능을 관찰하기 위하여 $700^{\circ} \mathrm{C}$ 에서 소성 열화한 촉매를 $\mathrm{Fe}$ 의 함량을 달리하여 $400^{\circ} \mathrm{C}$ NSR 흡장성능을 측정하였다.

Fig. 6에 나타난 바와 같이 $0 \%, 2 \%, 5 \% \mathrm{Fe}$ 가 함침 된 촉매는 흡장성능의 차이가 크지 않지만, $10 \% \mathrm{Fe}$ 가 함침 된 촉매는 흡장성능이 우수함을 알 수 있으 며, 연속된 농후 조건에서는 첨가된 $\mathrm{Fe}$ 함량에 관계 없이 환원성은 그대로 유지하는 것을 관찰할 수 있다.

$\mathrm{Fe}$ 의 존재는 일정 온도에서 심층 $\mathrm{BaSO}_{4}$ 크기 성 장을 제한하여 작은 결정 크기로 $\mathrm{BaSO}_{4}$ 를 분산시키 므로 작은 크기의 $\mathrm{BaSO}_{4}$ 는 재생이 쉬우며, 열에도 강한 내열성을 가진 것으로 알려져 있으며, 이에 따 라, 흡장 성능이 개선되는 것으로 판단된다 ${ }^{3,5)}$

Table 3에 열화 된 촉매들의 $\mathrm{NO}_{\mathrm{x}}$ 흡장량을 수치로 나타내었다. $\mathrm{Fe}$ 가 함침되지 않은 $\mathrm{Pt} / \mathrm{Co} / \mathrm{Ba} / \mathrm{Al}_{2} \mathrm{O}_{3}$ 촉 매의 흡장성능은 소성온도가 $400^{\circ} \mathrm{C}$ 일 때 $0.405 \mathrm{NO}_{\mathrm{x}}$ $\mathrm{mole} / \mathrm{Ba}$ mole이지만, $700^{\circ} \mathrm{C}$ 조건에서 소성후에는 $0.062 \mathrm{NO}_{\mathrm{x}} \mathrm{mole} / \mathrm{Ba}$ mole라는 상대적으로 낮은 흡장 성능을 나타내었다. 반면, $\mathrm{Fe}$ 가 첨가된 촉매의 흡장 성능은 소성온도가 $400^{\circ} \mathrm{C}$ 일 때 흡장 성능은 $0.5 \mathrm{NO}_{\mathrm{x}}$ $\mathrm{mole} / \mathrm{Ba}$ mole로 나타나며, $700^{\circ} \mathrm{C}$ 소성 후에는 0.24
Table 3 Effect of iron amount on NSR over thermally aged $3 \% \mathrm{Pt} / 2 \% \mathrm{Co} / 10 \% \mathrm{Fe} / \mathrm{BaO} / \mathrm{Al}_{2} \mathrm{O}_{3}$

\begin{tabular}{|c|c|c|c|c|c|}
\hline & $\begin{array}{l}\mathrm{Pt} \\
(\%)\end{array}$ & $\begin{array}{l}\text { Co } \\
(\%)\end{array}$ & $\begin{array}{l}\mathrm{Fe} \\
(\%)\end{array}$ & $\begin{array}{c}\text { Calci. Temp. } \\
\left({ }^{\circ} \mathrm{C}\right)\end{array}$ & $\begin{array}{c}\mathrm{NO}_{\mathrm{x}} \text { uptake } \\
\left(\mathrm{NO}_{\mathrm{x}} \text { mole/ }\right. \\
\mathrm{Ba} \text { mole })\end{array}$ \\
\hline \multirow{12}{*}{$\begin{array}{c}30 \% \mathrm{BaO} / \\
\mathrm{Al}_{2} \mathrm{O}_{3}\end{array}$} & 3 & 2 & - & 700 & 0.062 \\
\hline & 3 & 2 & 2 & 700 & 0.070 \\
\hline & 3 & 2 & 5 & 700 & 0.081 \\
\hline & 3 & 2 & 10 & 700 & 0.24 \\
\hline & 3 & 2 & - & 400 & 0.405 \\
\hline & 3 & 2 & - & 500 & 0.287 \\
\hline & 3 & 2 & - & 600 & 0.26 \\
\hline & 3 & 2 & - & 700 & 0.062 \\
\hline & 3 & 2 & 10 & 400 & 0.50 \\
\hline & 3 & 2 & 10 & 500 & 0.27 \\
\hline & 3 & 2 & 10 & 600 & 0.29 \\
\hline & 3 & 2 & 10 & 700 & 0.24 \\
\hline
\end{tabular}

$\mathrm{NO}_{\mathrm{x}}$ mole/ $\mathrm{Ba}$ mole로 나타나므로 $\mathrm{Fe}$ 가 첨가되지 않 은 $\mathrm{Pt} / \mathrm{Co} / \mathrm{Ba} / \mathrm{Al}_{2} \mathrm{O}_{3}$ 촉매의 흡장성능과 비교할시 상대 적으로 높은 흡장성능을 나타내었다.

\section{3 촉매 열화 특성 분석}

Fig. 4 Fig. 6에 나타난 NSR 흡장 결과에 기초한 Table 3으로 부터 $\mathrm{Pt} / \mathrm{Co} / \mathrm{Ba} / \mathrm{Al}_{2} \mathrm{O}_{3}$ 촉매를 고온으로 소성 시 흡장 성능이 감소하는 것을 관찰할 수 있다. 고온 소 성에 따른 촉매 특성 변화를 조사하기 위하여 XRD 분

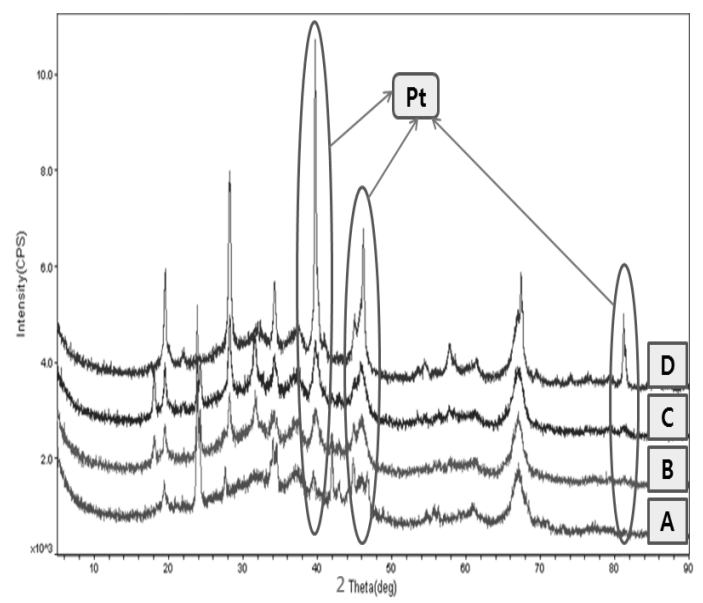

Fig. $7 \mathrm{XRD}$ result of $3 \% \mathrm{Pt} / 2 \% \mathrm{Co} / \mathrm{BaO} / \mathrm{Al}_{2} \mathrm{O}_{3}$ thermally aged at : a) $500^{\circ} \mathrm{C}$ b) $600^{\circ} \mathrm{C}$ c) $700^{\circ} \mathrm{C}$ d) $850^{\circ} \mathrm{C}$ 


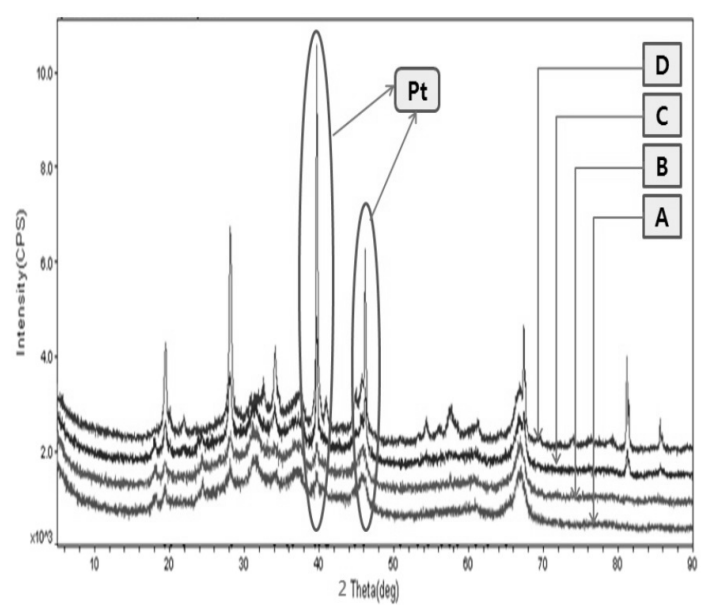

Fig. $8 \mathrm{XRD}$ result of $3 \% \mathrm{Pt} / 2 \% \mathrm{Co} / 10 \% \mathrm{Fe} / \mathrm{BaO} / \mathrm{Al}_{2} \mathrm{O}_{3}$ thermally aged at : a) $500^{\circ} \mathrm{C} \mathrm{b)} 600^{\circ} \mathrm{C}$ c) $700^{\circ} \mathrm{C}$ d) $850^{\circ} \mathrm{C}$

석(Fig. 7, Fig. 8)과 비표면적 분석(Table 4)을 하였다.

Fig. 7에 나타난 $\mathrm{XRD}$ 결과로 부터 $500^{\circ} \mathrm{C}$ 와 비교 하여 $600^{\circ} \mathrm{C}$ 에서는 $\mathrm{Pt}$ 소결이 심하게 이루어지지 않 는 것으로 관측되며, $700^{\circ} \mathrm{C}$ 이상에서는 $\mathrm{Pt}$ 검출선이 상대적으로 강하고 날카롭게 나타나므로, 열화에 인 한 백금 소결이 진행되었다고 판단된다. 따라서, $700^{\circ} \mathrm{C}$ 에서 소성된 $\mathrm{Pt} / \mathrm{Co} / \mathrm{Ba} / \mathrm{Al}_{2} \mathrm{O}_{3}$ 촉매의 $\mathrm{Pt}$ 소결이 $\mathrm{NSR}$ 성능 감소의 원인인 것으로 판단된다.

Fig. 8 의 $\mathrm{XRD}$ 결과로 부터 $\mathrm{Fe}$ 가 첨가된 $3 \% \mathrm{Pt} /$ $2 \% \mathrm{Co} / 10 \% \mathrm{Fe} / \mathrm{BaO} / \mathrm{Al}_{2} \mathrm{O}_{3}$ 촉매는 $500^{\circ} \mathrm{C}$ 와 비교하여 $700^{\circ} \mathrm{C}$ 까지 소성 온도가 증가하여도 $\mathrm{Pt}$ 소결이 상대적으로 작은 것으로 나타난다.

Table 3 에서 $700^{\circ} \mathrm{C}$ 에서 흡장된 $\mathrm{NO}_{\mathrm{x}} / \mathrm{Ba}$ 몰비는 0.24 으로 나타난다. Table 3 에 나타난 흡장량에 근거 하여, $400^{\circ} \mathrm{C}$ 에서 소성된 촉매와 비교하여 $700^{\circ} \mathrm{C}$ 에서 열회된 촉매는 $50 \% \mathrm{NO}_{\mathrm{x}}$ 흡장량을 유지하는 것으로 관측되므로 $\mathrm{Fe}$ 가 내열성 향상에 참여하는 것으로 판 단된다. $850^{\circ} \mathrm{C}$ 의 고온에서 소성된 경우 $\mathrm{Pt}$ 의 열화 소 결이 일어남을 알 수 있다. 따라서, 첨가된 $\mathrm{Fe}$ 가 촉매 의 내열성을 향상시키는 것으로 판단된다 ${ }^{8,9)}$.

Table 4 는 $3 \% \mathrm{Pt} / 2 \% \mathrm{Co} / 10 \% \mathrm{Fe} / \mathrm{BaO} / \mathrm{Al}_{2} \mathrm{O}_{3}$ 촉매의 $\mathrm{BET}$ 비표면적을 온도별로 구분하였다. BET 비표면 적을 비교해보면 촉매의 열화온도가 높아질수록 비 표면적이 감소하는 것을 알 수 있다. $400^{\circ} \mathrm{C}$ 부터 $600^{\circ} \mathrm{C}$
Table 4 Effect of calcination temperature on surface area of $3 \% \mathrm{Pt} / 2 \% \mathrm{Co} / 10 \% \mathrm{Fe} / \mathrm{BaO} / \mathrm{Al}_{2} \mathrm{O}_{3}$

\begin{tabular}{c|c}
\hline \hline Calcination Temperature $\left({ }^{\circ} \mathrm{C}\right)$ & Surface area $\left(\mathrm{m}^{2} / \mathrm{g}\right)$ \\
\hline 400 & 117.1 \\
\hline 500 & 116.9 \\
\hline 600 & 106.1 \\
\hline 700 & 99.1 \\
\hline \hline
\end{tabular}

까지는 비표면적의 감소가 크지 않으며, $700^{\circ} \mathrm{C}$ 부터 비표면적의 감소가 나타나지만, Table 3에 나타난 $400^{\circ} \mathrm{C}$ 에서 $700^{\circ} \mathrm{C}$ 소성 후의 $\mathrm{NO}_{\mathrm{x}}$ 흡장면적 감소율과 비교하여, 비표면적 감소율은 상대적으로 작은 것으 로 나타난다.

따라서, 소성 온도가 증가함에 따라 NSR 흡장면 적이 급격히 낮아지지만, BET 비표면적 변화량은 많 지 않으므로 담체인 $\mathrm{Al}_{2} \mathrm{O}_{3}$ 비표면적은 열화에 큰 영 향을 받지 않는 것으로 판단되며, $\mathrm{BET}$ 결과와 XRD 결과로부터 고온으로 소성한 촉매의 흡장성능 감소 는 Pt 열화 소결에 의한 것으로 판단된다.

\section{4. 결 론}

$\mathrm{XRD}$ 분석에 의하여 $\mathrm{Fe}$ 첨가된 촉매는 열화후 $\mathrm{Pt}$ 소결의 진행도가 상대적으로 느린 것으로 나타나며, $\mathrm{NSR}$ 결과로부터 $\mathrm{NO}_{\mathrm{x}}$ 흡장량은 $\mathrm{Fe}$ 가 첨가 안된 촉매 보다 상대로 높은 $\mathrm{NO}_{\mathrm{x}}$ 흡장량을 유지하였다. $\mathrm{BET}$ 표면적 측정에 의하여 열화 후에도 촉매의 비표면적 감소는 적은 것으로 나타난다. 따라서 열화에 의한 $\mathrm{Pt}$ 소결이 $\mathrm{NO}_{\mathrm{x}}$ 흡장량을 감소시키며 $\mathrm{Fe}$ 는 열화에 의 한 $\mathrm{Pt}$ 결정 소결을 억제하는 것으로 나타난다.

\section{참 고 문 헌}

1. S. S. Kim, D. Y. Kim and J. G. Kim, "Effect of change of hydrocarbon reductant on HC-SCR over Fe/ZSM-5 catalyst". Trans. Korean and New energy Soc., Vol. 23, No. 2 (2011) pp. 265-273.

2. S. S. Kim, D. Y. Kim and J. G. Kim, "Effect of Change of Hydrogen Rich Reductant on HC-SCR over Co-Pt/ ZSM5 Catalyst", Trans. Korean and New energy Soc., Vol. 23, No. 3 (2012) pp. 199-206. 
3. J. Y. Luo, M. Meng, Y. Q. Zha, Y N. Xie, T. D. Hu., J. Zhang and T. Liu, "Comparative study of $\mathrm{Pt} / \mathrm{Ba} / \mathrm{Al}_{2} \mathrm{O}_{3}$ and $\mathrm{Pt} / \mathrm{Fe}-\mathrm{Ba} / \mathrm{Al}_{2} \mathrm{O}_{3}$ NST catalyst: New Mission into the interaction or Pt-Ba and the function of Fe', Appl. Catal. B: Env., Vol. 78 (2008) pp. 38-52.

4. K. Yamazaki, N. Y Takahashi, H. Shinjoh, and M. Sugiura, "The performannce of $\mathrm{NO}_{\mathrm{x}}$ storage reduction catalyst containing Fe-compound after thermal aging”, Appl. Catal B: Env., Vol. 53 (2004) pp. 1-12.

5. K. Yamazaki, T. Suzuki, N. Takahashu, K. Yokota and M. Sugira, "Effect of the addition of transition metals to $\mathrm{Pt} / \mathrm{Ba} / \mathrm{Al}_{2} \mathrm{O}_{3}$ catalyst on the $\mathrm{NO}_{\mathrm{x}}$ storage-reduction catalysis under oxidizing conditions in the presence of $\mathrm{SO}_{2}$, Appl. Catal. B: Env., Vol. 30 (2001) pp. 459-468.

6. P. T. Fanson, M. R. Horton, W. N. Delgass and J. Lauterbach, "FTIR analysis of storage behavior and sulfur tolerance in barium based $\mathrm{NO}_{\mathrm{x}}$ storage and reduction (NSR) catalysts", Appl. Catal. B: Env., Vol. 46 (2003) pp. 393-413.

7. S. Salasc, M. Skoglundh and E. Fridell, "Comarison between $\mathrm{Pt}$ and $\mathrm{Pd}$ in $\mathrm{NO}_{\mathrm{x}}$ storage catalyst", Appl. Catal. B. Env. Vol. 36 (2002) pp. 145-169.

8. X. Chen, J. Schwank, J. Li, W. F. Schneider, C. T. Goraski and P. J. Schmitz, "Thermal decomposition of dispersed and bulk-like $\mathrm{NO}_{\mathrm{x}}$ species in model $\mathrm{NO}_{\mathrm{x}}$ trap materia”, Appl. Catal. B.: Env., Vol. 61 (2005) pp. 164-175.

9. J. G. Kim, H. M. Lee, M. J. Lee and S. S. Kim, et al., "Effect of $\mathrm{Co}$ an $\mathrm{Rh}$ promoter on $\mathrm{NO}_{\mathrm{x}}$ storage and reduction over $\mathrm{Pt} / \mathrm{BaO} / \mathrm{Al}_{2} \mathrm{O}_{3}$ catalyst", JICHE, Vol. 14 (2008) pp. 841-846. 